\author{
๑ Л. В. Дубик \\ ВДНЗ «Буковинсъкий державний медичний університет», Чернівиі
}

\title{
РОЛЬ СИСТЕМИ ГЕМОСТАЗУ В ПАТОГЕНЕЗІ РЕПРОДУКТИВНИХ ВТРАТ
}

Мета дослідження - оцінити зміни деяких показників гемостазу в І триместрі вагітності в жінок із спонтанним абортом. Матеріали та методи. Нами було обстежено 153 вагітних, які перебували на стаціонарному лікуванні в гінекологічному відділенні КМУ «МКПБ № 1», а також перебували на обліку в Жіночій консультації № 1.3 них 30 жінок були із неускладненою вагітністю в терміни 6-12 тиж. (I група), 60 - із загрозою мимовільного аборту (II група), 34 - зі спонтанним абортом (III група) і 29 - 3 вагітністю, що не розвивається (IV група).

Результати дослідження та їх обговорення. У більшості вагітних із невиношуванням ранньої вагітності на момент обстеження були виявлені порушення в системі гемостазу, що свідчили про збільшення потенціалу згортання крові (гіперкоагуляцію). Так, показником активації внутрішнього шляху згортання служить зменшення величини активованого часткового тромбопластинового часу $(\mathrm{P}<0,05)$. Кількість фрібриногену в групі із самовільним перериванням вагітності і вагітністю, що не розвивається, перевищує показники при неускладненій вагітності I триместру удвічі (Р<0,05). Аналіз агрегаційної активності тромбоцитів пацієнток із невиношуванням вагітності в ранні терміни виявив невелике, але достовірне збільшення агрегації тромбоцитів порівняно з показником при фрізіологічній вагітності $(P<0,05)$.

Висновок. У жінок із невиношуванням вагітності спостерігаються зміни зі сторони системи гемостазу, які проявляються явищами гіперкоагуляції та активацією внутрішнього шляху згортання крові.

Ключові слова: невиношування вагітності; тромбоцити; фрібриноген; агрегація тромбоцитів.

РОЛЬ СИСТЕМЫ ГЕМОСТАЗА В ПАТОГЕНЕЗЕ РЕПРОДУКТИВНЫХ ПОТЕРЬ

Цель исследования - оценить изменения некоторых показателей гемостаза в I триместре беременности у женщин со спонтанным абортом.

Материалы и методы. Нами было обследовано 153 беременных, пребывающих на стационарном лечении в гинекологическом отделении КМУ «ГКРД № 1», а также состоящих на учете в Женской консультации № 1. Из них 30 женщин были с неосложненной беременностью в сроки 6-12 нед. (I группа), 60 - с угрозой самопроизвольного аборта (II группа), 34 - со спонтанным абортом (III группа) и 29 - с беременностью, которая не развивается (IV группа).

Результаты исследования и их обсуждение. У большинства беременных с невынашиванием ранней беременности на момент обследования были обнаружены нарушения в системе гемостаза, свидетельствующие об увеличении потенциала свертывания крови (гиперкоагуляции). Так, показателем активации внутреннего пути свертывания служит уменьшение величины активированного частичного тромбопластинового времени $(\mathrm{P}<0,05)$. Количество фрибриногена в группе с самовольным прерыванием беременности и беременностью, которая не развивается, превышает показатели при неосложненной беременности I триместра вдвое $(\mathrm{P}<0,05)$. Анализ агрегационной активности тромбоцитов пациенток $\mathrm{C}$ невынашиванием беременности в ранние сроки показал небольшое, но достоверное увеличение агрегации тромбоцитов по сравнению с показателем при физиологической беременности $(\mathrm{P}<0,05)$.

Вывод. У женщин с невынашиванием беременности наблюдаются изменения со стороны системы гемостаза, проявляющиеся явлениями гиперкоагуляции и активацией внутреннего пути свертывания крови.

Ключевые слова: невынашивание беременности; тромбоциты; фрибриноген; агрегация тромбоцитов.

THE ROLE OF HEMOSTASIS SYSTEM IN PATHOGENESIS OF REPRODUCTIVE LOSSES

The aim of the study - to evaluate changes in some hemostatic indices in the first trimester of pregnancy in women with spontaneous abortion.

Materials and Methods. We examined 153 pregnant women who had been in inpatient treatment at the Gynecological Department of the Municipal Health Care Facility "City Clinical Maternity Hospital No. 1, and are also registered in the WellWoman Clinic No. 1. Among them, 30 women were with uncomplicated pregnancy for 6-12 weeks (Group I), 60 women were with the threat of miscarriage (Group II), 34 women were with spontaneous abortion (Group III) and 29 women were with blighted ovum (Group IV).

Results and Discussion. At the time of the survey the violations in the hemostasis system were revealed in most cases of early pregnancy loss, indicating an increase in the potential for blood coagulation (hypercoagulation). Thus, the index of activation of the internal coagulation pathway is a decrease in the value of the activated partial thromboplastin time $(P<0.05)$. The number of fibrinogen in a group with unauthorized termination of pregnancy and blighted ovum is twice that in case of uncomplicated pregnancy in the first trimester $(P<0.05)$. The analysis of aggregation activity of platelets in patients with early pregnancy loss revealed a small, but a significant increase in platelet aggregation compared to an indicator in case of physiological pregnancy $(P<0.05)$.

Conclusion. The changes of the system of hemostasis are observed in women with miscarriages, which are manifested by the phenomena of hypercoagulation and activation of the internal pathway of blood coagulation.

Key words: miscarriage; platelets; fibrinogen; platelet aggregation. 
ВСТУП. Переривання вагітності на ранніх термінах $€$ однією із провідних проблем акушерства. Втрата бажаної вагітності спостерігається у 30 \% випадків, і немає тенденції до зменшення цього показника [1]. На жаль, у більш ніж половині випадків причини викидня залишаються невідомими, навіть після проведення ретельної діагностики [2].

Останнім часом з'являється чимало публікацій, що вказують на велику роль тромбофрілічних ускладнень при репродуктивних втратах [3-5]. Згідно з дослідженнями, в організмі вагітної жінки створюються певні умови для розвитку синдрому дисемінованого внутрішньосудинного згортання. Це проявляється підвищенням загального коагулянтного потенціалу (сумарна активність фракторів згортання), підвищенням фрункціональної активності тромбоцитів при деякому зниженні їх кількості, послабленням фрібринолітичної активності антитромбіну III при деякому зменшенні його вмісту. Ці особливості є компенсаторно-пристосовними і потрібні як для нормального фрормування фетоплацентарного комплексу, так і для обмеження крововтрати під час пологів.

Патогенетичні механізми переривання вагітності ранніх термінів обумовлені переважно активацією системи гемостазу і реалізуються зазвичай через патологію судинної стінки, розвиток інфрарктів плаценти, що проявляється симптомами відшарування трофобласта або хоріона [6]. На думку дослідників, у 80 \% пацієнток із втратою вагітності ранніх термінів виявляються гемостазіологічні зміни, що сприяють гіперкоагуляції [7]. При цьому є дані, що при вагітності, яка не розвивається, явища гіперкоагуляції характерні в 100 \% випадків.

Порушення адаптаційних процесів під час вагітності пов'язані з високим ризиком венозного, артеріального і плацентарного тромбозу. Формування цієї патології з ранніх термінів гестації призводить до ускладнень гестаційного процесу, зокрема до невиношування вагітності [8].

MЕТА ДОСЛІДЖЕННЯ - оцінити зміни деяких показників гемостазу в I триместрі вагітності в жінок із спонтанним абортом.

МАТЕРІАЛИ ТА МЕТОДИ. Нами було обстежено 153 вагітних, які перебували на стаціонарному лікуванні в гінекологічному відділенні КМУ «МКПБ № 1», а також перебували на обліку в Жіночій консультації № 1. 3 них 30 жінок були із неускладненою вагітністю в терміни 6-12 тиж. (І група), 60 - із загрозою мимовільного аборту (II група), 34 - зі спонтанним абортом (III група) і 29 - 3 вагітністю, що не розвивається (IV група).

Вік обстежених вагітних коливався в межах 18-45 років. Критеріями включення в обстеження були: наявність абортів і репродуктивних втрат в анамнезі; відсутність гінекологічних та екстрагенітальних захворювань у гострій і підгострій стадіях.

РЕЗУЛЬТАТИ ДОСЛІДЖЕННЯ ТА ЇХ ОБГОВОРЕННЯ. Проведені дослідження показали, що в жінок II групи (загроза викидня) спостерігається тенденція до зменшення кількості тромбоцитів $(P>0,05)$, у той час як при спонтанному аборті та вагітності, що не розвивається, зареєстровано достовірне зниження цього показника - $(198,7 \pm 34,3)$ і $(189,4 \pm 38,5)$ Г/л відповідно порівняно 3 рівнем при фрізіологічній вагітності - $(286,3 \pm 22,2)$ Г/л ( $\mathrm{P}<0,05$, табл. 1).

У більшості вагітних з невиношуванням ранньої вагітності на момент обстеження були виявлені порушення в системі гемостазу, що свідчили про збільшення потенціалу згортання крові (гіперкоагуляцію). Так, показником активації внутрішнього шляху згортання служить зменшення величини активованого часткового тромбоплас-

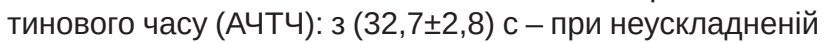
вагітності до $(24,9 \pm 2,6)$ с у пацієнток з вагітністю, що не розвивається $(P<0,05)$. У представниць II і III груп обстежених цей показник мав тенденцію до зменшення, однак достовірної різниці не досяг.

При неускладненій ранній вагітності рівень фрібриногену становив $(2,98 \pm 0,51)$ г/л, практично не відрізняючись від фрізіологічного значення невагітних жінок [9]. Однак при загрозі самовільного викидня цей показник досягав значення $(4,63 \pm 0,66)$ г/л, що, попри відсутність достовірного виходу за межі нормативних величин, характеризувався чіткою тенденцією до зростання. Зате у пацієнток III і IV груп рівень фрібриногену статистично вагомо підвищувався, становлячи, відповідно, $(5,88 \pm 1,24)$ і $(6,32 \pm 1,50)$ г/л $(\mathrm{P}<0,05)$. Аналіз рівня фрібриногену у межах II, III і IV груп досліджуваних жінок достовірної різниці не виявив. У групі із самовільним перериванням вагітності і вагітністю, що не розвивається, кількість фрібриногену перевищує показники при неускладненій вагітності I триместру удвічі - $(5,88 \pm 1,24)$ i $(6,32 \pm 1,50)$ г/л (табл. 1, рис. 1).

Значення протромбінового індексу (ПТІ), що характеризує зовнішній шлях згортання, при неускладненій вагітності супроводжувалося тенденцією до збільшення, однак не перевищувало максимального рівня нормальних величин $(P>0,05)$.

У пацієнток із невиношуванням вагітності в ранні терміни ПТІ коливався від $(108,1 \pm 3,3)$ до $(110,4 \pm 8,5) \%$, а аналіз агрегаційної активності клітин, що стимулюють аденозиндифосфат, виявив невелике, але достовірне збільшення агрегації тромбоцитів порівняно з показником при фрізіологічній вагітності - $(39,5 \pm 0,4) \%$. Так, у жінок зі спонтанним абортом і вагітністю, що не розвивається, агрегація тромбоцитів до колагену досягала $(40,9 \pm 0,5)$ i $(41,2 \pm 0,6) \%$ відповідно $(P<0,05)$. Як і раніше, достовірної

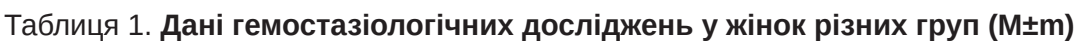

\begin{tabular}{|l|c|c|c|c|}
\hline \multicolumn{1}{|c|}{ Показник } & $\begin{array}{c}\text { I група } \\
\text { (різіологічна } \\
\text { вагітність), } \mathrm{n=30}\end{array}$ & $\begin{array}{c}\text { II група (загроза } \\
\text { самовільного } \\
\text { аборту), } \mathrm{n=60}\end{array}$ & $\begin{array}{c}\text { III група } \\
\text { (спонтанний } \\
\text { аборт), } \mathrm{n=34}\end{array}$ & $\begin{array}{c}\text { IV група } \\
\text { (вагітність, що не } \\
\text { розвивається), } \mathrm{n=29}\end{array}$ \\
\hline Кількість тромбоцитів, г/л & $286,3 \pm 22,2$ & $239,5 \pm 16,5$ & $198,7 \pm 34,3$ & $189,4 \pm 38,5$ \\
\hline АЧТЧ, с & $32,7 \pm 2,8$ & $28,6 \pm 1,9$ & $26,3 \pm 2,4$ & $24,9 \pm 2,6$ \\
\hline Фібриноген, г/л & $2,98 \pm 0,51$ & $4,63 \pm 0,66$ & $5,88 \pm 1,24$ & $6,32 \pm 1,50$ \\
\hline ПТІ, \% & $90,4 \pm 8,3$ & $108,1 \pm 3,3$ & $104,5 \pm 7,6$ & $110,4 \pm 8,5$ \\
\hline Агрегація тромбоцитів до колагену, \% & $39,5 \pm 0,4$ & $40,2 \pm 0,3$ & $40,9 \pm 0,5$ & $41,2 \pm 0,6$ \\
\hline
\end{tabular}




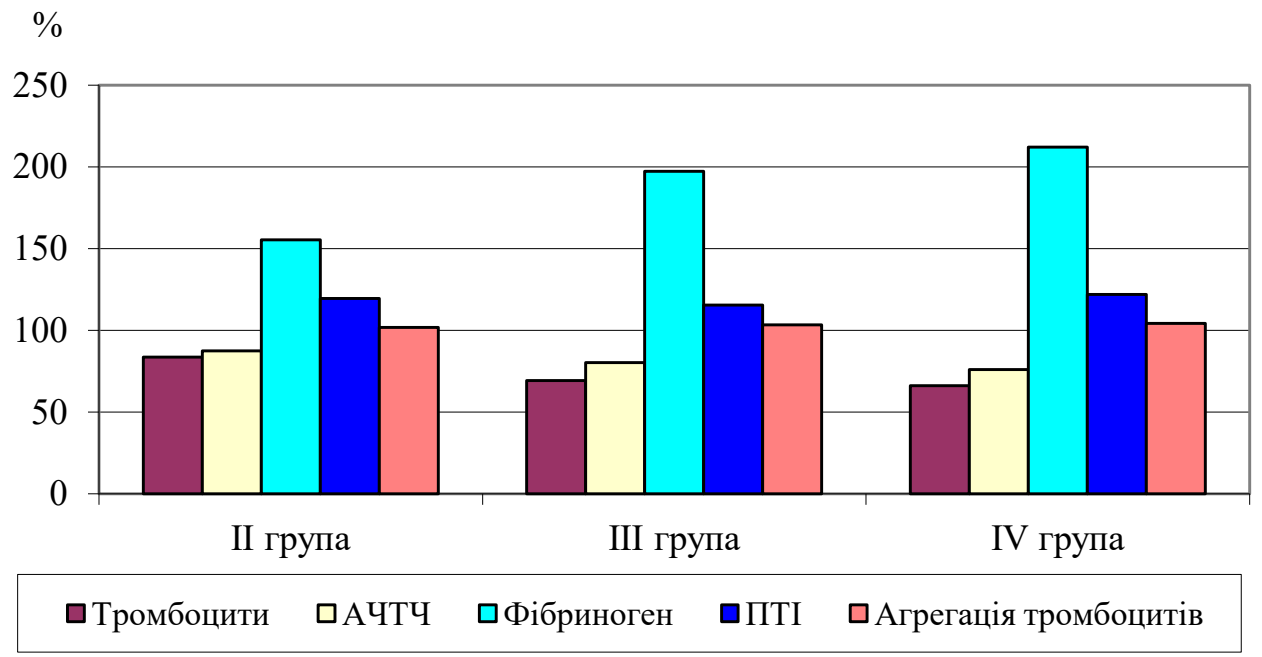

Рис. 1. Зміна показників гемостазу жінок із невиношуванням вагітності в ранні терміни порівняно з фізіологічною вагітністю (у \%).

різниці між значеннями цього показника у межах II, III і IV груп не встановлено (Р>0,05, табл. 1, рис. 1).

ВИСновкИ. 1. Проведені дослідження показали, що в жінок із загрозою викидня спостерігається тенденція до зменшення кількості тромбоцитів, у той час як при спонтанному аборті та вагітності, що не розвивається, зареєстровано достовірне зниження цього показника $(\mathrm{P}<0,05)$

2. У більшості вагітних із невиношуванням ранньої вагітності на момент обстеження були виявлені порушення в системі гемостазу, що свідчили про збільшення потенціалу згортання крові (гіперкоагуляцію).

3. Показником активації внутрішнього шляху згортання служить зменшення величини активованого часткового тромбопластинового часу $(P<0,05)$.

\section{СПИСОК ЛІТЕРАТУРИ}

1. Born too soon: the global epidemiology of 15 million preterm births / H. Blencowe, S. Cousens, D. Chou [et al.] // Reprod Health. - 2013. - Vol. 10. - P. S2. doi: 10.1186/17424755-10-S1-S2.

2. Ткаченко В. Б. Оцінка ризику спонтанного викидня залежно від генетичних характеристик жінки / В. Б. Ткаченко, А. С. Раздайбєдіна, І. І. Воробйова // Перинатология и педиатрия. - 2018. - № 1 (73). - С. 74-79.

3. Репина М. А. Наследственные нарушения системь гемостаза и беременность : методические рекомендации / М. А. Репина, Г. Ф. Сумская, Е.Н.Лапина; под ред. Э. К. Айламазяна. - СПб. : Изд-во Н-Л, 2008. - 40 с.

4. Антифоссролипидный синдром - иммунная тромбофилия в акушерстве и гинекологии / [А. Д. Макацария, В. О. Бицадзе, С. М. Баймуродова и др.]. - М. : Триада-Х, 2007. -456 c.

5. Клеточная диагностика возможности витальной компьютерной микроскопии / И. А. Василенко, В.П. Тычинский,
4. Кількість фрібриногену в групі із самовільним перериванням вагітності і вагітністю, що не розвивається, перевищує показники при неускладненій вагітності І триместру удвічі $(\mathrm{P}<0,05)$.

5. Аналіз агрегаційної активності тромбоцитів пацієнток із невиношуванням вагітності в ранні терміни виявив невелике, але достовірне збільшення агрегації тромбоцитів порівняно 3 показником при фрізіологічній вагітності $(P<0,05)$.

ПЕРСПЕКТИВИ ПОДАЛЬШИХ ДОСЛІДЖЕНЬ. ВРаховуючи отримані результати, можна стверджувати, що подальші дослідження будуть мати вагоме наукове значення і практичне застосування, з метою профрілактики невиношування вагітності.

А. Л. Валов [и др.] // Вестник последипломного медицинского образования. - 2009. - № 3-4. - С. 64-68.

6. Значение локальных клеточных взаимодействий в эндометрии в процессе вынашивания беременности / Е. М. Демидова, В. Е. Радзинский, Н. Н. Волощук [и др.] // Вопросы гинекологии, акушерства и перинатологии. -2006. - Т. 5, № 1. - С. 67-74.

7. Олусола А. Д. Эндотелиальная диссрункция в генезе ранних репродуктивных потер : автореф. дисс. на соискание науч. степени канд. мед. наук / А. Д. Олусола.- М., 2012. - 22 c.

8. Recurrent miscarriage and long-term thrombosis risk: a case-control study / S. Quenby, R. G. Farquharson, F. Dawood [et al.] // Hum. Reprod. -2015. - Vol. 20, No. 6. - P. 1729-1732.

9. Физиологические изменения в организме женщины во время беременности // Новости медицины и фрармации [Электронный ресурс]. - 2016. - URL : http://www.mif-ua.com/ education/symposium/fiziologicheskie-izmeneniya-v-organizmezhenshiny-vo-vremya-beremennosti. 


\section{REFERENCES}

1. Blencowe, H., Cousens, S., Chou, D., Oestergaard, M., Say, L., Moller, A.-B., ... \& Lawn, J. (2013). Born too soon: the global epidemiology of 15 million preterm births. Reprod. Health, 10, S2. doi: 10.1186/1742-4755-10-S1-S2.

2. Tkachenko, V.B., Razdaibiedina, A.S., \& Vorobiova, I.I. (2018). Otsinka ryzyku spontannoho vykydnia zalezhno vid henetychnykh kharakterystyk zhinky [Assessment of the risk of spontaneous miscarriage depending on the genetic characteristics of a woman]. Perynatolohiia i pediatriia. Ukraina - Perinatology and Pediatrics Ukraine, 1 (73), 74-79 [in Ukrainian].

3. Riepina, M.A., Sumska, H.F., \& Lapina, E.N. (2008). Nasledsvennye narusheniya sistemy gomeostaza i beremenost: metodicheskiye rekomendatsii [Hereditary disorders of the hemostatic system and pregnancy: Methodical recommendations]. Aylamazyana, (E.K.) (Ed.). Saint-Petersburg: Iz-vo N-L [in Russian].

4. Makatsariya, V.O. (Ed.). (2007). Antyfosfolipidnyy sindrom - imunnaya trombofiliya $v$ akusherstve $i$ ginekologii [Antiphospholipid syndrome - the immune thrombophilia in obstetrics and gynecology]. Moscow: Triada-KH [in Russian].

5. Vasilenko, I.A., Tychynskiy, V.P., \& Valov, A.L. (2009). Kletochnaya diagnostika vozmozhnosti vitalnoy kompyuternoy mikroskopii [Cellular diagnostics of the possibility of the vital computed microscopy]. Vestnik poslediplomnogo meditsinskogo obrazovaniya - Bulletin of Postgraduate Medical Education, 3-4, 64-68 [in Russian].

6. Demidova, Ye.M., Radzinskiy, V.E., \& Voloshchuk, G.G. (2006). Znacheniya lokalnykh kletochnykh vzayemodeystviy v endometrii v protsese vynashyvaniya beremenosti [The importance of local cellular interactions in the endometrium during pregnancy]. Pytannia hinekolohii, akusherstva ta perynatolohii - Questions of Qynecology, Obstetrics and Perinatology, 5, 1, 67-74 [in Russian].

7. Olusola, A.D. (2012). Endotelialnaya disfunktsiya v geneze rannikh reproduktivnykh poter [Endothelial dysfunction in the genesis of early reproductive loss]. Candidate's Extended abstract. Moscow [in Russian].

8. Quenby, S., Farquharson, R.G., \& Dawoodetal, F. (2015). Recurrent miscarriage and long-term thrombosis risk: a casecontrol study. Hum. Reprod., 20, 6, 1729-1732.

9. (2016). Fiziologichiskiye izmeneniya v organizme zhenshchiny vo vremya beremenosti [Physiological changes in the body of a woman during pregnancy]. Novosti meditsyny i farmatsii News of Medicine and Pharmacy. Retrieved from: http://www. mif-ua.com/education/symposium/fiziologicheskie-izmeneniyav-organizme-zhenshiny-vo-vremya-beremennosti [in Russian]. 